\title{
Application of Big Data Analysis Methods for Technology Foresight in Strategic Emerging Industries
}

\author{
Liu Yufei ${ }^{1}$, Zhou Yuan ${ }^{2}$, Liao Ling ${ }^{3}$ \\ 1. College of Life Science \& Technology, Huazhong University of Science and Technology, Wuhan 430074, China \\ 2. School of Public Policy and Management, Tsinghua University, Beijing 100084, China \\ 3. School of Mechanical Science \& Engineering, Huazhong University of Science and Technology, Wuhan 430074, China
}

\begin{abstract}
Technology foresight is receiving increasing attention as an innovative strategic management tool. Considerable research has been conducted on technology foresight methods and their applications. The theoretical difficulty is how to conduct technology foresight for different types of emerging industries, especially for the type of industry innovations pursued in developing countries. Delphi expert analysis is currently the most popular technology-foresight method. This method's reliability and validity are deficient because it lacks objective data to support expert experience. The authors propose a new method for integrating patents and technical documents into the technology foresight of China's emerging industries.
\end{abstract}

Keywords: technology foresight; bibliometrics; patent analysis; big data analysis; emerging industry

\section{Importance of big data analysis in technology foresight of strategic emerging industries}

\subsection{Strategic emerging industries occupy an important position in national economic development}

In the 21 st century, a country's scientific and technological innovation capacity has become an important measurement index of its overall national strength and the focus of international competition [1]. Worldwide technological and industrial revolutions, facilitated by a transformation in the economic development of China, have entered a historic cross road. Particularly, a new industrial revolution is emerging, and global technology development has given rise to new and intensive innovations [2]. The development of strategic emerging industries is an important strategic decision, considering the international economic situation and future sustainable development in a country. Strategic emerging industry will become an important focal point of China's future economic growth, industrial transformation and upgrading, and innovation-driven developments. Fostering and developing strategic emerging industries, building a modern industrial system at a high starting point, accelerating the formation of new economic growth, and seizing the commanding heights of future economic and technological development, all have significant strategic significance in determining whether our economy and society can truly embark on an innovation-driven, endogenous growth, sustainable development track. A report on the 18th National Congress of the Communist Party of China clearly states that an important measure for promoting the strategic adjustment of the economic structure, accelerating the transformation and upgrades of traditional industries, optimizing the industrial structure, and promoting sustained and healthy

Received date: 25 May 2016; revised date: 26 June 2016

Author information: Liu Yufei, College of Life Science \& Technology, Huazhong University of Science and Technology. His current research is big data analysis method supporting the engineering science and technology strategic consulting. E-mail: liuyufei0418@qq.com

Foundation program: CAE Major Advisory Project "Research on Promotion and Development Planning of China's Strategic Emerging Industry in the 13th Five-Year Plan Period" (No. 2014-ZD-7); Project of China Knowledge Center for Engineering Sciences and Technology (CKCEST-2015-4-2); Project of the National Natural Science Foundation of China (No. L1524015, 71203117, 71233005); Sub-Project of Green Economy and Sustainable Development Research Center of Tsinghua University (No. 20153000181)

Chinese version: Strategic Study of CAE 2016, 18 (4): 121-128

Cited item: Liu Yufei, Zhou Yuan, Liao Ling. Application of Big Data Analysis Methods in Technology Foresight for Strategic Emerging Industries. Strategic Study of CAE, http://10.15302/J-SSCAE-2016.04.018 
economic development is to actively promote the development of strategic emerging industries. Therefore, it is essential to learn the laws of developing strategic emerging industries and identify their development direction, which can help to accelerate the cultivation and development of strategic emerging industries.

Cultivating and developing strategic emerging industries and enhancing the independent innovation capability are necessary to meet the needs of national economic development. Moreover, the industrial upgrade brought by revolution in science and technology should also be considered, while simultaneously grasping future development trends of industrial core technologies. The necessity and importance to carry out planned technologydevelopment forecast work must be recognized by all countries [3-7]. The United States, Britain, Germany, Korea, and other countries, through national-level monitoring of technological development, carry out forecasting of technology tendencies for the next 10-20 years. Furthermore, they create science and technology plans and action plans to improve the efficiency of resource allocation, which has achieved remarkable success. For example, the indicator of external technology dependency accounts for approximately $5 \%$ in Japan, Germany, South Korea, the United States, Britain, and other countries.

\subsection{Technology foresight plays an important role in the development of strategic emerging industries}

Technology foresight has gained increasing attention in various countries, and has become a new technological strategic management tool. However, its characteristic of combination with science, technology, economics, management, and other interdisciplinary also increases the difficulty of accurate technology foresight work. The main objectives of technology foresight are to explore a country's future technology needs, identify future key research areas, and draw up scientific and effective development planning. In order to better enhance our capacity of independent innovation, it is important to develop a research mechanism and management mode to constantly improve the judgment on future technology needs of the country and the ability to forecast technology trends by carrying out technology foresight continuously [8].

Although researchers are beginning to focus on technology foresight for the development of strategic emerging industries [9], important theoretical and methodological problems still exist. Studies in recent years suggest that the formation and development of emerging industries have four main different paths [10]: industry regeneration, industry differentiation, industry derivation, and industrial integration. These different paths require differentiated technology-foresight theories and methods. In addition, China and other developing countries are in a transition period to follow the international forefront level in terms of industry technological innovation. China, as well as other countries, must catch up to the current world level of innovation in the development of emerging industries and technologies. Closing the innovation gap, which presents new challenges, must be incorporated into our technology-foresight theories and methods [11]. Therefore, to determine how to implement technology foresight for emerging industries of different paths, we need to specifically consider innovation deficiencies in developing countries, which is a theoretical problem in urgent need to be further discussed for technology foresight.

\subsection{Big data analysis will play an important role in technology foresight}

With the explosive growth of information on macro-industry development strategies and technology foresight, relying entirely on an expert's limited knowledge domain for directional judgment has become increasingly controversial. Instead, effective use of big data can help experts solve the problem of information collection and analysis through complete information collection and screening, data collation and analysis, as well as indexing and graphing information and data, making them devote more energy in the judgment and proposal of technology foresight and strategic issues. Therefore, effective use of big data is the development direction of technology foresight. Note that the purpose of using big data methods is to support, rather than to replace decision-makers. The goal of these methods is to enable experts to spend more time and energy on their area of expertise, such as judgments and recommendations, and to ultimately improve the quality of strategic consulting services. There are some application problems that need to be addressed, such as how to embed objective data into technology foresight processes of strategic emerging industries by using big data analysis methods, how to provide experts with data support, making them give full play to the professional knowledge and rich experience, and reduce subjective bias to improve reliability and validity of technology foresight.

Based on the papers and patent data of strategic emerging industries, big data analysis of patents and literature studies relevant information contained in papers and patent data, and further analyzes the hotspots and frontiers of related technologies, development trends, national comparisons, and enterprise competitiveness by using literature metrology, data mining, data analysis, and other methods [12-16]. Some scholars also apply data analysis to technology foresight work; however, they tend to provide data analysis as a part of the background information of technology foresight to experts in the field [17-21]. Few experts combine data analysis with expert experience to produce interactions throughout the process of technology foresight in order to study future technology trends and strategic planning [21-29]. Although research on the interaction between data and experts has resulted in certain outcomes [31-34], large-scale application of data analysis methods in practical consulting work is still lacking. Based on the background of studying and establishing 
the national medium- to long-range programs for scientific and technological development, research on technology foresight and key technology selection have sufficient scientific and practical significance for the formulation of China's macro-development strategy.

Therefore, based on theoretical design and in-depth applied research of case, this paper establish an analytical framework and process for emerging industry technology foresight on account of patent literature and other big date, which can improve the ability to search and use data, strengthen data analysis capabilities, and enable data analysis of patents and literature streamline and systemize, while enhancing usability and lowering the threshold of use. This paper uses objective analysis methods, such as literature metrology, patent analysis, technology roadmaps, and other methods, to improve the existing consultation process, screen and analyze the background information of this project. This paper also provides development routes of relevant technical researches and research hotspots at home and abroad, forecasts technical trends, and generates analysis reports for expert and scholarly to establish a more applicable and effective set of strategic consulting process and analysis frameworks for emerging industrial technology foresight in the era of big data. In order to deepen the theoretical understanding, simplify the process and apply tools in emerging industry technology foresight of systematic technology development strategies, it is necessary to take full advantage of big data concepts and methods in the basis of expert decision-making.

\section{Primary exploration of big data analysis to support technology foresight}

To better play the role of data in supporting strategic consulting, it is necessary to implement a standardized design of the consultation process and framework, carry out in-depth research and development of data analysis methods and tools, and conduct investigation and analysis of major strategic emerging industrial projects to generate data analysis reports of higher pertinence, which can better meet the data needs of experts and academicians as well as the majority of researchers, can be able to provide strong knowledge support for major strategic consulting and to offer decision support in strategic emerging industries.

In this paper, in order to eventually establish a support platform with wide applicability, strong usability, and low degree of operation difficulty for academicians and experts, consulting staff, and general strategic emerging industry researchers, the big data analysis method is embedded into the consultation process by means of a functional module. The functional module strengthens the data collection and processing capacity in studying the strategic emerging industries, extends data mining capabilities, and enhances analysis capabilities of association between data. At the same time, the functional module has been promoted and tried to run in key consultation projects to provide knowledge support for academicians and experts and to improve the quality of consulting services.

Therefore, big data analysis methods that support technology foresight will be discussed from the following three aspects of strategic emerging industries: process design of strategic consulting, development of analysis module for research data of strategic consulting, and case studies on the application of strategic consulting method.

\subsection{Process design for strategic consulting of strategic emerging industry}

According to the present situation and development trend of the domestic and foreign strategic consulting, and the research characteristics of it, the consultation process are standardized, and the big data analysis methods are combined with advisory services in consultation process stage. By considering the experience accumulated in completed consulting projects from various sources, different data analysis methods in classifying various consulting projects were used to collect and analyze data involved in the projects. These projects can be divided into three categories:

\subsubsection{Type of analysis on strategic planning evolution}

This type refers to conduct the comprehensive analysis on academic papers, patent results, and industry development reports of this project field. Furthermore, it specifies the time for the transformation of research results into industrial processes, making use of data to discover an industry focus to provide support for experts' judgment.

\subsubsection{Type of technology foresight}

This type conducts data mining and analysis of historical data in this project field, summarizes development trends, technology routines, and relevant outcome distributions, as well as predicts alternative popular technology as the reference for experts.

\subsubsection{Type of evaluation}

In this category, the projects are evaluated mainly from the relative achievements of the project and its change trends in this project field before and after the start-up of the project.

Fig. 1 shows the workflow chart of the currently implemented consulting project.

This type summarizes and sorts procedure of different projects, and builds process database for retrieval in future consulting projects.

\subsection{Analysis module development of research data for strategic consulting of strategic emerging industries}

The framework design of the data analysis module requires the following basic functional modules: database, method base, and index base. 


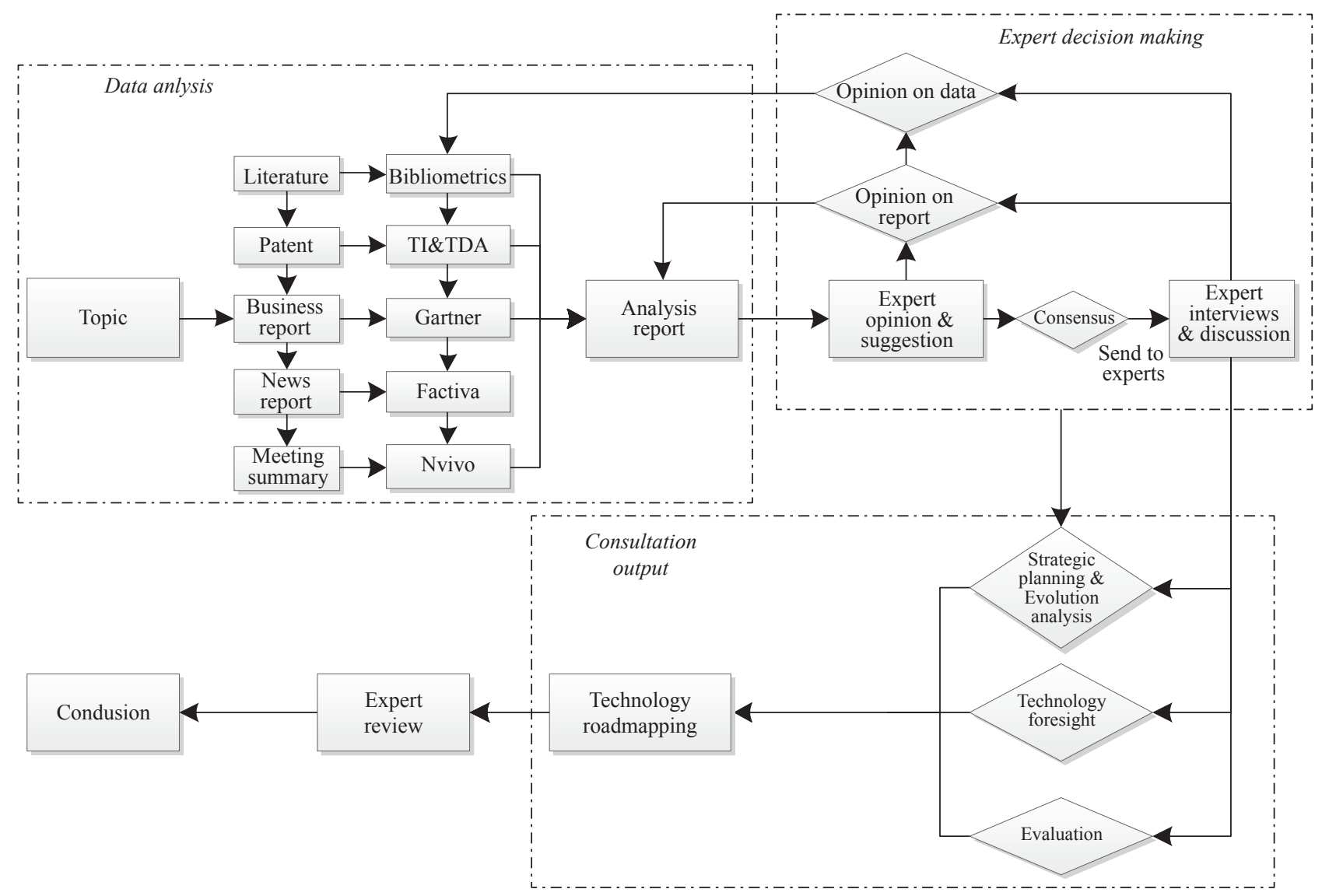

Fig. 1. Workflow chart of consulting project.

\subsubsection{Database}

The authors build a multi-dimensional database for each specific project to carry out subsequent data mining and analysis by using the scientific literature, patent documents, business reports, news reports, meeting minutes, and other data resources available at the Chinese Academy of Engineering and Tsinghua University. At present, there are preliminarily several databases can be used, such as Chinese paper data from the China National Knowledge Infrastructure, English paper data from the Web of Science, patent data from Thomson Innovation (TI), Gartner's business reports, and Factiva's news reports.

\subsubsection{Method base}

The main purpose of data mining and data analysis during the platform construction is to filter the data in the database according to project needs, and to make correlation analyses for different types of data. The quality of the data source is the most important factor in determining the quality of analysis results; therefore, in the integration process, literature metrology, text mining, patent analysis, structured subject-verb-object (SAO) analysis of text data preprocessing, and other methods are used to filter data sources to best meet the desired needs. Then, databaserelated software is used in each category to analyze the data from the filtered data sources. Based on the results, further procedures such as primary path analysis, technology roadmaps, and other methods, are applied to assess, screen, and optimize the results that are more in line with the strategic consulting requirements of strategic emerging industries. Lastly, the authors apply the association rules, clustering, classification, prediction, and other data mining methods to make a comprehensive analysis of the data of different categories and generate an analysis report which can provide the reference for academicians and experts.

A number of data analysis software can be applied in the research work of strategic consulting, such as the text mining software in Thomson Data Analyzer (TDA), analysis software of NVivo Qualitative Data, network analysis software of UCINET, and analysis tools of Pajek for large and complex network.

Although many research institutions have already used data, relevant software, and data mining methods for analysis, few research institutions use a variety of databases for problem analysis and conduct a correlation analysis of different types of data. The proposed platform aims to adopt an integrated and innovative approach by using information and analysis software in a variety of data bases to select, integrate, and optimize the data of each category. Furthermore, this integrated approach creates an organic data link with complementary advantages, thereby correlating data of different categories in a certain area.

\subsubsection{Index base}

Currently, both the patent analysis indicators and the paper 
analysis indicators have accumulated a certain amount of research results. The main indicators are shown in Table 1 and Table 2.

\subsection{Application of strategic consulting methods in a case study}

Emerging industry in China has three main forms: (1) lag

Table 1. Patent analysis indicators.

\begin{tabular}{|c|c|c|}
\hline Measuring index & Calculation method & Definition of index, indexical meaning \\
\hline Number of patents & $\begin{array}{l}\text { Calculate number of patents including a } \\
\text { technical point }\end{array}$ & $\begin{array}{l}\text { Describe invention activities of the technology industry. Larger } \\
\text { numbers indicate more invention activities of the technology industry }\end{array}$ \\
\hline $\begin{array}{l}\text { Technology growth rate } \\
(v)\end{array}$ & $\begin{array}{l}v=a / A \text {, where } a \text { represents the number of } \\
\text { invention patents that year and } A \text { is the number } \\
\text { of invention patents in the past five years }\end{array}$ & $\begin{array}{l}\text { By calculating } v \text { for consecutive years, if } v \text { increasing trend is detected, } \\
\text { the technology is in the growing stage }\end{array}$ \\
\hline
\end{tabular}

Technology maturing $\quad \alpha=a /(a+b)$, where $a$ is the number of patents factor $(\alpha)$ applied that year, and $b$ is the number of utility model patents applied that year

Technology aging coefficient $(\beta)$

$\beta=(a+b) /(a+b+c)$, where $a$ is the number of invention patents applied for that year, $b$ is the number of utility model patents applied for that year, and $c$ is the number of designs or trademarks applied for that year

Number of patent granted Country of priority refers to the total number of by US patents of "US"

Patent Cooperation Treaty Country of priority refers to the total number of (PCT) application number patents of "WO"

Patent growth rate

$$
R=\frac{P a(n)-P a(n-1)}{P a(n-1)}
$$

$(P a(n)$ denotes the number of patents in the $n$th year)

Current impact index (CII) The CII is the enterprise's current cited ratio of patents in the historical five-year period divided by all patent cited ratios

Technical strength (TS) Patent amount of the technical point multiplied by the CII

Technical independence

Patent self-citations of the technical point is divided by patent total self-citations of technical point

Technical impact index (TII)

Rate of patent for invention

Forward citations

The ratio from number of patents of the most influential among the top $10 \%$ citations of a year dividing by patent year amount is divided by the ratio from number of patents of the most influential among all patents dividing by all patent amounts of the technical point

Number of invention patent of the technical point is divided by total number of invention patent of the technical point

Times that a patent is cited by later patents

Science correlation degree Average cited times of scientific literature
By calculating the value of $\alpha$ for consecutive years, if $\alpha$ diminishing trend is observed, the technology is in the mature stage

By calculating the value of $\beta$ for consecutive years, if $\beta$ decreasing trend is observed, the technology is gradually becoming obsolete

For high-tech patent numbers, the greater the index, the higher technical content of the technology

The PCT international application reflects the importance of the technology contained in the patent and the applicant's urgent desire to share on the international market. The patent quality can be measured to some extent; the larger the index, the higher the patent quality and the higher the level of technical activities

The patent growth rate reflects the degree of change in technology innovation capability. Higher indexes indicate enhanced ability of the technology innovation

CII reflects the technical strength and technology leadership level of the technology. Larger indexes indicate greater technical strength of a research institution or enterprise technology and a higher leading level.

TS reflects the innovation quality of a technical point; the higher the value of the TS, the higher innovation capability and quality of technology relevant to research institutions and enterprises

This index reflects the degree of dependence of technical point and the independence level of research and development. Higher indexes indicate a lower dependence of the technology on other technologies and a higher independence level of research and development

This index reflects the technology-leading level of an enterprise better than the CII. The larger the TII, the stronger the technology and strength of relevant research institutions and enterprises and a higher degree of lead

This index measures the technology development stage of a technology point. Higher indexes indicate the technology point is in the germination or development stage, while lower indexes indicate that the technology is more mature

This index measures the impact of the patent on future technology development. Higher indexes indicate the technical basis is more basic or more important

This index reflects the degree of relation between a technical point involved in the technological field and science; larger indexes indicate that research and development activities and technological innovation closely follow the development of the latest technologies 
Table 2. Paper analysis indicators.

\begin{tabular}{|c|c|c|}
\hline Measuring index & Calculation method & Definition of index, indexical meaning \\
\hline $\begin{array}{l}\text { Average number of papers } \\
\text { published in partition }\end{array}$ & $\begin{array}{l}\text { Calculate papers in } \mathrm{ABCD} \text { four partitions (number } \\
\text { of papers divided by number of periodicals in the } \\
\text { partition) }\end{array}$ & $\begin{array}{l}\text { This index reflects the number of papers of different research } \\
\text { levels at the technical point and aids in the level of understanding } \\
\text { of academic research activities pertaining to the technical point }\end{array}$ \\
\hline Paper composite indicator & $\begin{array}{l}\text { Number of papers published in the partition multiplied } \\
\text { by the average impact factor of the partition }\end{array}$ & $\begin{array}{l}\text { This index reflects the level of academic research activity on } \\
\text { the technical point. The higher the index, the higher the level of } \\
\text { academic research on this technology point }\end{array}$ \\
\hline Document growth rate & $\begin{array}{l}\quad R=\frac{P a(n)-P a(n-1)}{P a(n-1)} \\
(P a(n) \text { denotes the number of literature published in the } \\
n \text {th year) }\end{array}$ & $\begin{array}{l}\text { The document growth rate reflects the degree of change in } \\
\text { technology innovation capabilities. Higher indexes indicate the } \\
\text { innovation ability of the technology is more enhanced }\end{array}$ \\
\hline Cited amount per paper & $\begin{array}{l}\text { Total cited times of a paper divided by the total number } \\
\text { of papers }\end{array}$ & $\begin{array}{l}\text { In theory, cited times is a scale to measure the influence and } \\
\text { quality of an academic paper. Higher indexes indicate stronger } \\
\text { importance and status of this technology point }\end{array}$ \\
\hline
\end{tabular}

behind in the whole, continuing to catch up; (2) synchronize in theory, backwards in application; and (3) be advanced on the whole, manufacturing leading. The main foresight work differs for different types of emerging industries. Therefore, the authors conduct a specific study of technology foresight for three typically emerging industries, including the robotics industry, the three-dimensional (3D) printing industry, and the new energy and energy conservation industry.

\subsubsection{Robot industry}

The theory, technology and market applications of the robot industry in China lag behind in the whole, but they are beginning to catch up with the world's advanced technology. When technology foresight is conducted for such emerging industries, the gap between China's robot technologies and the world's advanced level must be firstly clarified, and then the reasons for these gaps must be analyzed. Finally, we must find out the technology points to close these gaps and to guide industry development. The main research contents are as follows: this paper identified the science, technology and industrial applications of the robot industry, as well as the gap among them in the transfer process based on the literature metrology and patent analysis methods; combining the historical data and expert knowledge, this paper identified the future policy, market, industry, and other macroeconomic factors that cause the innovation gaps in the robot industry; this paper drew a robot industry technology roadmap to guide industry development.

\subsection{2. $3 \mathrm{D}$ printing industry}

A theoretical study of the $3 \mathrm{D}$ printing technology in China is keeping pace with the world's advanced level, but market applications are relatively behind. When conducting technology foresight for such emerging industries, first, it is necessary to carry out technology foresight at the world's advanced level; second, special attention must be paid to the coordinated transformation from basic research and development to industrial technology. Therefore, it is necessary to maintain cutting-edge research and in-depth exploration of technological research focuses, technol- ogy gaps, technology development trends, and other aspects, to maintain overall advancement, comprehensive strength, and competitiveness of theoretical research. The study will mainly focus on empirical research on identification of emerging technology, scientific bases, influences, etc. The main research contents are as follows: analysis and discovery of emerging technologies based on patent data; basic analysis of emerging technology science based on papers and patent data; analysis of the potential impact of emerging technologies based on network information data.

\subsubsection{New energy and energy conservation industry}

Research on new energy and energy-saving technologies in our country, as a whole, is at the advanced level of the world. Therefore, when conducting technology foresight on such emerging industries, the industrial technology development will be the main focus, because the development of such industries is relatively in mature stage and China enjoys outstanding manufacturing advantages. In addition, according to the industry characteristics above all, technology development and foresight of the entire topic can be carried out. The main contents are as follows: combining the literature metrology, patent analysis, network analysis, and a technology roadmap to explore, discuss and recognize the technology development stage of the new energy and energy-saving technologies; using the literature metrology to identify the evolution process from science to technology; applying patent analysis to recognize the conversion process from technology to application; and applying technology roadmap to discuss and recognize the promotion from application to market.

\section{Prototype for strategic consulting and research supporting platform of strategic emerging industries}

This study systematically designed a standard analysis framework of technology foresight to better meet experts' demands for patent, literature and other data, providing strong knowledge support for an emerging industry development strategy, and to 
more scientifically play a supporting role of experts in emerging industrial technology foresight and strategic planning. This paper proposes to design four modules, including a database, methods and tools base, index base, and process base, to better complete data collection, data mining, and data analysis work. Using these modules, a technology foresight theoretical framework can be constructed based on big data analysis.

Finally, a prototype for comprehensive strategic consulting supporting platform, which integrates high-quality data sources, advanced analytics, comprehensive analysis of indicators, effective consultation processes, and extensive consulting cases, is established, as shown in Fig. 2.

In the building process of platform, this paper conducted an in-depth analysis of domestic and foreign technology-foresight theory and application problems, explored the intrinsic link between objective big data, technology roadmaps, etc. and expert knowledge, constructed big data analytics, analysis framework and process about a technology roadmap embedded in the tech- nology foresight, and optimized experts-core decision support processes.

In order to explore and study the analysis framework and process of aforementioned embedded technology foresight, this platform on the one hand will study integrating points of big data analysis, technology roadmaps, and technology foresight. On the other hand, it will realize innovation, development, and applications of specific methods and tools according to the integrating points.

This platform applied big data concepts, methods, and a technology foresight framework into the practical case studies of robotics, 3D printing, and new energy and energy conservation to construct index, explore emerging technologies within specific industrial and technical fields as well as their future development paths, and explore factors affecting development of emerging technologies and the changes in the relationships between these factors, all of which can provide a scientific basis and decision support for emerging technologies and industries.

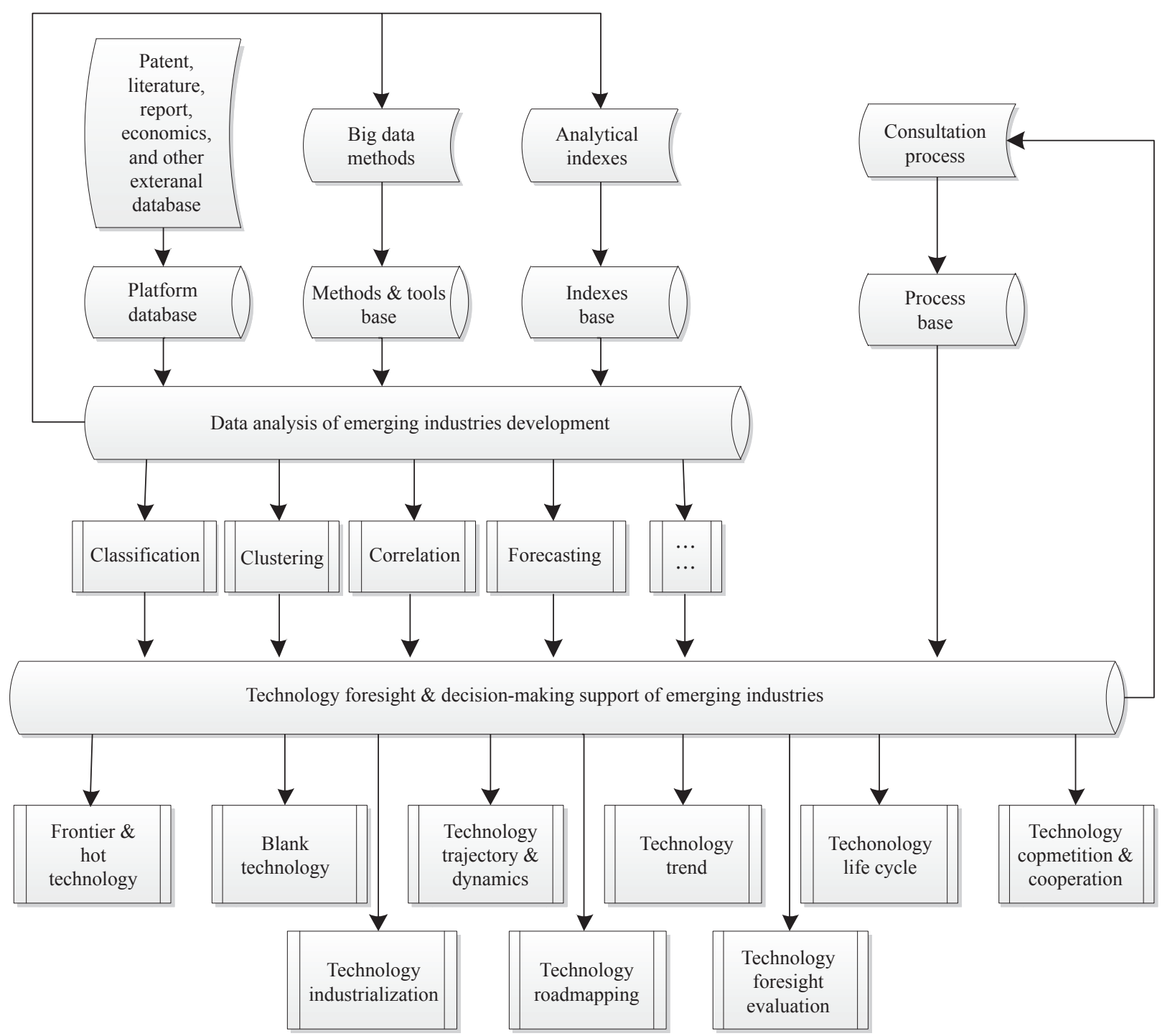

Fig. 2. Prototype for strategic consulting and research support platform of strategic emerging industry. 


\section{References}

[1] Miles I. The development of technology foresight: a review [J]. Technological Forecasting and Social Change, 2010, 77 (9): 14481456.

[2] Blind K, Cuhls K, Grupp H. Current foresight activities in central Europe [J]. Technological Forecasting and Social Change, 1999, 60 (1): $15-35$.

[3] Georghiou L. The UK technology foresight program [J]. Futures, 1996, 28 (4): 359-377.

[4] Martin B R, Johnston R. Technology foresight for wiring up the national innovation system: experiences in Britain, Australia, and New Zealand [J]. Technological Forecasting and Social Change, 1999, 60 (1): 37-54.

[5] Kuwahara T. Technology forecasting activities in Japan [J]. Technological Forecasting and Social Change, 1999, 60 (1): 5-14.

[6] Lee S K, Mogi G, Kim J W. Energy technology roadmap for the next 10 years: the case of Korea [J]. Energy Policy, 2009, 37 (2): 588-596.

[7] Choi M, Choi H L, Yang H, et al. Characteristics of 4th Korean technology foresight $[\mathrm{C}]$. In: Institute of Electrical and Electronics Engineers. 2012 Proceedings of PICMET'12: Technology Management for Emerging Technologies (PICMET). New York: IEEE, 2012: 1330-1354.

[8] Guo W D. Technology foresight theory method and key technology innovation model research [D]. Beijing University of Posts and Telecommunications, 2007. Chinese.

[9] Xue L, Zhou Y, Li Y B, et al. Strategic emerging industries and industrial policy research on innovation [M]. Science press, 2015 Chinese.

[10] Lee S, Seol H. Using patent information for designing new product and technology: keyword based technology roadmapping [J]. R\&D Management, 2008, 38 (2): 169-188.

[11] Phaal R, O'Sullivan E, Routley M, et al. A framework for mapping industrial emergence $[\mathrm{J}]$. Technological Forecasting and Social Change, 2011, 78 (2): 217-230.

[12] Daim T, Rueda G, Martin H, et al. Forecasting emerging technologies: use of bibliometrics and patent analysis [J]. Technological Forecasting and Social Change, 2006, 73 (8): 9811012.

[13] Li X, Huang L C. Visualization analysis of dye-sensitized solar cells technology based on bibliometric [J]. Journal of Intelligence, 2013, 32 (12): 98-103. Chinese.

[14] Jun S, Lee S J. Emerging technology forecasting using new patent information analysis [J]. International Journal of Software Engineering and its Applications, 2012, 6 (3): 107-114.

[15] Kim Y G, Suh J H, Park S C. Visualization of patent analysis for emerging technology [J]. Expert Systems with Applications, 2008, 34 (3): 1804-1812

[16] Zhang Y, Wang X F, Guo Y, et al. Technology roadmap to construct model based on the method of literature metrology research $[\mathrm{J}]$. Studies in Science of Science, 2012, 30 (4): 495-502. Chinese.

[17] Guo Y, Wang X F, Zhu D H, et al. "LIP-to-down" science and technology planning: a new approach based on the patent data and technology roadmapping [J]. Studies in Science of Science, 2012, 30 (3): 349-358. Chinese.

[18] Robinson D K R, Huang L, Guo Y, et al. Forecasting innovation pathways for new and emerging science and technologies [J]. Technological Forecasting and Social Change, 2013, 80 (2): $267-$ 285.

[19] Li X, Huang L C. Emerging industry based on the technology roadmap forming path research [J]. Science and Technology Progress and Countermeasures, 2014, 31 (1): 44-49. Chinese.

[20] Li X, Zhou Y, Xue L, et al. Integrating bibliometrics and roadmapping methods: a case of dye-sensitized solar cell technology-based industry in China [J]. Technological Forecasting and Social Change, 2015, 97: 205-222.

[21] Qiao Y. Application of patent bibliometrics methods in technology foresight - take the subsection of metallurgy as an example [J]. Journal of Intelligence, 2013, 32 (4): 34-37. Chinese.

[22] Wang J P. Technology forecast method based on the scientific measurement optimization research [D]. Wuhan: Central China Normal University, 2011. Chinese.

[23] Cui Z M, Wan J B, Pu G X, et al. The basic principles of technology foresight and national key-technology choice in China [J]. Science of Science and Management of S\&T, 2002, 23 (12): 9-12. Chinese.

[24] Wang X C, Wu T F, Jiang X R, et al. Empirical research on patent intelligence analysis oriented to technology forecast $[\mathrm{J}]$ Information Science, 2014, 32 (7): 139-144. Chinese.

[25] Mu R P, Ren Z B, Yuan S D, et al. The study on methodology of Delphi survey of technology foresight of China towards 2020 [J]. Journal of Scientific Research Management, 2006, 27 (1): 1-7. Chinese.

[26] Sun J F, Yuan J H, Zhao Y, et al. Research on foreign aerospace technology to foresee the future development $[\mathrm{J}]$. Aerospace Chinese, 2015 (10): 37-41. Chinese.

[27] Zhang Y, Zhang G Q, Chen H S, et al. Topical analysis and forecasting for science, technology and innovation: methodology with a case study focusing on big data research [J]. Technological Forecasting and Social Change, 2016, 105: 179-191.

[28] Wang X F, Qiu P J, Zhu D H, et al. Identification of technology development trends based on subject-action-object analysis: the case of dye-sensitized solar cells [J]. Technological Forecasting and Social Change, 2015, 98: 24-46.

[29] Nassirtoussi A K, Aghabozorgi S, Wah T Y, et al. Text mining of news-headlines for FOREX market prediction: a multi-layer dimension reduction algorithm with semantics and sentiment [J] Expert Systems with Applications, 2015, 42 (1): 306-324.

[30] Keppell M. Principles at the heart of an instructional designer: subject matter expert interaction [C]. In: Sims R, O’ Reilley M, Sawkins S, et al. Learning to choose-choosing to learn. Proceedings of the 17th annual conference of the Australasian Society for computers in learning in tertiary education, 2000 , Coffs Harbour, NSW. Australia: ASCILITE, 2000: 317-326.

[31] Quiamzade A, Mugny G, Cléopas A D, et al. Interaction styles and expert social influence [J]. European Journal of Psychology of Education, 2003, 18 (4): 389-404.

[32] Lee M F, Mehlenbacher B. Technical writer/subject-matter expert Interaction: the writer's perspective, the organizational challenge [J]. Technical Communication, 2000, 47 (4): 544-552.

[33] Kenny P G, Parsons T D, Gratch J, et al. Evaluation of novice and expert interpersonal interaction skills with a virtual patient $[\mathrm{J}]$. Lecture Notes in Computer Science, 2009, 5773: 511-512. 